provider of equal opportunity for all children, it is imperative that the great majority of children should have opportunities of enjoying the benefits that highly skilled and, therefore, highly trained teachers can confer.

The National Union of Teachers fears most that, although the evidence for the maximum provision of educational opportunity at the earliest stages may be accepted, the form of school organization indicated may be rejected because of the anxiety that now exists about the supply of teachers in the immediate future. The Union urges that no purely economic considerations should be allowed to lead to legislation that will permanently warp the present primary-school system-a system which for many reasons is educationally desirable.

\title{
INTRODUCED SPECIES OF AMPHIBIA AND REPTILIA IN MAINLAND BRITAIN
}

$\mathrm{T}$

HE native fauna of mainland Britain is small compared with that of continental Europe. In the last glaciation of the Ice Age, the great ice sheets stretched almost as far south as the Thames, and only with their recession could the fauna of warmer climates spread back from the southern part of Europe. At that time the area which is now the English Channel was occupied by dry land, so that movement across it was relatively easy. With the invasion of the sea and the opening of the Channel Gap some 5,000 years ago, those species which had already entered the country were separated from those which had not yet reached so far north. Since then, any changes in the British fauna can only be due to extinction of some, and further passage across the sea by others, whether aided or unaided by man. In the case of amphibia and reptiles, such passage (apart from the occasional turtles) has invariably been aided.

The surviving species of amphibia and reptilos which reached Britain unaided comprise only two toads, one frog, three newts, three snakes and three lizards. Species used in attempts at naturalization far outnumber these, yet success has been infrequent. The motives for the enlargements of alien species appear to have been varied, ranging between curiosity to seo if they could establish themselves, or the liberation of captive specimens, the discarding of unwanted pets or even the escape of captive specimens. Casual escapes are unlikely to have taken place in such numbors as to form broeding populations except in the case of common pets such as tortoises. In the British Journal of Herpetology (3; June 1964), J. F. D. Frazer, of the Nature Conservancy, has classified the introduced species as follows: (a) Species which cannot survive Britain's normal conditions of weather, terrain and soil. These must be presumed to include the Madeiran wall lizard, the eyed lizard, the European wall lizard L. campestos (at least under conditions where it has been liberated hitherto), and the platanna, Xenopus laevis. (b) Specios which can survive under normal conditions, but which are killed in exceptionally severe winters, for example, Ewing's tree-frog. (c) Species of which the adults can survive even under severe conditions, but where breeding never takes place, or only in exceptional summers. These include the snapper and other American terrapins, the Greek tortoise, the geckos, the green lizard and the bullfrog. The fire-bellied toad is also included here. (d) Species of which the eggs can normally hatch or the young be born, but cannot reach adulthood. These may possibly include the green tree-frog in some parts of Britain. (e) Species which have not been introduced originally in sufficient numbers to produce success. The painted frog and fire salamander come into this group, which also probably includes a number of introductions of green tree-frogs, where not enough have been liberated in one place to allow sufficient females to survive until the next breeding season. There is the further complication that this species is imported in large numbers when taken at the broeding ponds, so that there will be far fewer females than males, and a whole consignment of 500 may contain only one or two females. At best, an unsorted batch of 100 liberated would only bo expected to contain about ten females. $(f)$ Species which apparently succeed in establishing themselves, but then go into decline. The major example of this is the edible frog, assuming that it was never native to the fen district. Its final decline can be associated with the destruction of its habitat, and it may be significant that its disappearance in East Anglia coincided with changes in land management and with increasing use and pollution of the waterways, while the decline in the traditional cutting and use of reed was associated with a great silting-up procoss. It may be that the fading fortunes of such a species are due to its changing environment becoming unsuitable for it. $(g)$ Finally, the species which seem to have colonized the land successfully have either been deposited in a suitable habitat, as in the case of the marsh frog, wall lizard ( $L$. muralis and $L$. nigriventris) and some successful colonies of green tree-frog; or, as with the alpine newt, midwife and yellow-bellied toads, have been fairly inconspicuous species which are not particularly specialized in their requirements. In this connexion it is interesting to contrast the breeding failures of the fire-bellied toad, which lives in and around shallow water in lowland terrain, with its congener, the yellow-bellied toad. This is more a creature of mountain streams, and it must have found the Devon hills to its liking.

\section{SPECULATION ON THE ORIGIN AND NON-SYMMETRY OF TWO THIN LAYERS $D^{\prime \prime}$ AND F EMBRACING THE LIQUID CORE INSIDE THE EARTH}

\author{
BY DR. V. S. TUMAN \\ Stanford Research Institute, Menlo Park, California
}

$I^{\mathrm{N}}$ general the Earth is considered to be formed of a thin crustal layer covering a fairly thick mantle which embraces its core. Bullen ${ }^{1}$ utilized seismic data to form a model of Earth subdivided into eight regions. The crustal layers form region $A$, which hæs an averago of $33 \mathrm{~km}$ thickness. Mantle, forming the regions $B, C$ and $D^{\prime}$, extends to a depth of $2,700 \mathrm{~km}$ and is followed by a region $D^{\prime \prime}$, which extends from 2,700 to $2,900 \mathrm{~km}$. The core is subdivided into three regions, $E, F$ and $G$.

The two layors $D^{\prime \prime}$ and $F$ embrace the outer core, layer $E$, which is generally considered to be liquid because it does not transmit the shear waves ${ }^{2}$. The nature and 